\title{
ETNOBOTANI UPACARA ADAT PAMOLE BEO OLEH SUKU DAYAK TAMAMBALOH DI DESA BANUA UJUNG KECAMATAN EMBALOH HULU KABUPATEN KAPUAS HULU
}

\author{
(Etnobotany Traditional Ceremonies Pamole Beo By The Dayak Tamambaloh Tribe Of Banua \\ Ujung Village, Kapuas Hulu District)
}

\author{
Dwi Seftiana Anggreini, Gusti Eva Tavita, Lolyta Sisilia \\ Fakultas Kehutanan Universitas Tanjungpura. Jl. Daya Nasional Pontianak 78124 \\ E-mail: $\underline{\text { dwianggreini22@gmail.com }}$
}

\begin{abstract}
Utilization of local plants, which are considered to have a meaning that has long been used by traditional communities for the needs of traditional ritual facilities, one of which is the Dayak Tamambaloh community in Kapuas Hulu District. This study aims to obtain data and determine the types of plants for the traditional pamole beo ritual ceremony by the Dayak Tamambaloh tribe in Banua Ujung Village, Embaloh Hulu District, Kapuas Hulu Regency. Pamole Beo is a form of gratitude for the harvest that has been obtained, and there are three stages of traditional rituals, namely maumpan karue, pamindara banyia, and malao daun takalong. The research used a survey method. The technique of determining respondents using snowball sampling. The results showed that the plants used by the Dayak Tamambaloh Tribe were 20 species from 12 families. The highest habitats were trees with 7 species (35\%). The highest utilization, based on status in nature, is natural plants in the forest (75\%.) The most widely used part of the plant is stems (40). Use value (UV) to determine plant species that have high utility in the community, namely Schizostachyum Sp, Arenga pinnata Merr, Oriza sativa Var. glutinosa and Cotylelobium melanoxylon (1). Informants Concensus Factor (ICF) To test the agreement between respondents and plants used for each category of ritual, the highest was the malao leaf takalong ritual (0.94). Family Importance Value (FIV) Analysis. Identifying the most widely used family of plant species, the highest were Arecaceae, Dipterocarpaceae, and Poaceae, as much as (100\%)
\end{abstract}

Keywords: Dayak Tamambaloh, Ethnobotany, Pamole Beo

Abstrak

Pemanfaatan tumbuhan lokal, yang di nilai memiliki makna tersendiri telah lama digunakan oleh masyarakat tradisional untuk kebutuhan sarana ritual adat, salah satunya masyarakat Dayak Tamambaloh di Kabupaten Kapuas hulu. Penelitian ini bertujuan untuk mendapatkan data dan mengetahui jenis tumbuhan untuk upacara ritual adat pamole beo oleh suku Dayak Tamambaloh di Desa Banua Ujung, Kecamatan Embaloh Hulu, Kabupaten Kapuas Hulu. Pamole Beo adalah bentuk ucapan syukur atas hasil panen yang telah diperoleh, dan terdapat tiga tahapan ritual adat yaitu maumpan karue, pamindara banyia, dan malao daun takalong. Metode yang digunakan adalah metode survey. Teknik menentukan responden menggunakan snowball sampling. Hasil penelitian menunjukkan bahwa tumbuhan yang dimanfaatkan Suku Dayak Tamambaloh sebanyak 20 spesies dari 12 famili. Habitus tertinggi adalah pohon sebanyak 7 jenis (35\%). Pemanfaatan tertinggi, berdasarkan status di alam adalah tumbuhan alami di hutan (75\%.) Bagian tumbuhan yang paling banyak dimanfaatkan adalah batang (40\%). Use value $(U V)$ untuk mengetahui spesies tumbuhan yang memiliki kegunaan tinggi di masyarakat yaitu Schizostachyum Sp, Arenga pinnata Merr, Oriza sativa Var. glutinosa dan Cotylelobium melanoxylon (1). Informants Concensus Factor (ICF) Menguji kesepakatan antara responden dan tanaman yang digunakan untuk setiap kategori ritual, tertinggi adalah ritual malao daun takalong (0,94). Analisis Famili Importance Value (FIV) Mengetahui famili pada spesies 
tumbuhan yang paling banyak digunakan, tertinggi adalah Arecaceae, Dipterocarpaceae, dan Poaceae, sebanyak (100\%).

Kata kunci: Dayak Tamambaloh, Etnobotani, Pamole Beo

\section{PENDAHULUAN}

Hutan di Kalimantan Barat menyimpan keanekaragaman hayati yang tinggi, mulai dari keanekaragaman ekosistem, spesies dan genetik yang harus dijaga kelangsungannya untuk generasi yang akan datang. Indonesia sebagai negara yang kaya akan suku budaya masyarakat, juga kaya akan keanekaragaman jenis tumbuhan. Tumbuhan merupakan keanekragaman hayati yang selalu ada di sekitar kita, baik yang tumbuh liar ataupun yang sudah dibudidayakan. (Yuniati \& Alwi, 2010). Pemanfaatannya juga didukung oleh potensi pengetahuan tradisional yang dimiliki berbagai suku asli di Kalimantan.

Etnobotani merupakan studi mengenai interaksi langsung antara manusia dengan sumber daya tumbuhan (Iswandono $d k k$, 2015). Etnobotani memiliki potensi untuk mengungkapkan sistem pengetahuan tradisional suatu kelompok masyarakat atau etnis mengenai keanekaragaman sumberdaya hayati. Salah satu etnis asli yang terdapat pada Provinsi Kalimantan Barat yaitu suku Dayak Tamambaloh yang berada di Desa Banua Ujung Kecamatan Embaloh Hulu, Kabupaten Kapuas Hulu.

Masyarakat Dayak Tamambaloh merupakan salah satu sub suku etnis Dayak di Kabupaten Kapuas Hulu Provinsi Kalimantan Barat, yang telah tinggal dan bermukim secara menetap hidup dari generasi ke generasi di suatu wilayah adat. Suku Dayak Tamambaloh merupakan wilayah adat yang kaya akan keanekaragaman hayati dan budaya kearifan lokal. Kearifan lokal ini tercermin dalam kebiasaan masyarakat Dayak Tamambaloh dalam memanfaatkan tumbuhan yang berada disekitar hutan. Banyak ditemukan jenis-jenis tumbuhan untuk kegiatan ritual adat, seperti di Kabupaten Polewali, Sulawesi Barat. Diperoleh 20 spesies, yang dimanfaatkan oleh masyarakat adat kampung Renggeang (Gaby et al. 2019). Upacara adalah serangkaian tindakan atau perbuatan yang terikat pada aturan tertentu berdasarkan adat istiadat, agama dan kepercayaan.

Tumbuhan digunakan dalam berbagai upacara ritual adat, salah satunya upacara ritual adat pamole beo. Pamole Beo adalah bentuk ucapan syukur atas hasil panen yang telah diperoleh, dan memohon kepada $I$ Sampulo (Allah) agar pada tahun yang akan datang menghasilkan panen yang lebih baik. Upacara adat pamole beo biasanya di selenggarakan setiap tahun setelah panen raya yaitu bulan juli atau menjelang masyarakat membuka ladang baru. Pemanfaatan dan penggunaan tumbuhan untuk ritual adat pamole beo di Desa Banua Ujung, oleh masyarakat suku Dayak Tamambaloh sudah menjadi tradisi yang turun-temurun. Secara etnobotani, belum terdokumentasikan dengan baik, jenis-jenis tumbuhan yang digunakan masyarakat untuk ritual adat tersebut. Oleh sebab itu perlu adanya penelitian untuk dokumentasi secara tertulis agar pengetahuan dan pemanfaaatan tumbuhan serta makna penggunaan tumbuhan dalam ritual adat 
tersebut dapat dipahami oleh masyarakat suku Dayak Tamambaloh supaya tetap lestari.

Penelitian ini bertujuan untuk mengetahui dan memperoleh data jenis tumbuhan yang digunakan dalam upacara adat Pamole beo, makna penggunaannya, tingkat pengetahuan etobotani dan nilai kepentingan tumbuhan pada setiap ritual dalam upacara Pamole beo (syukuran hasil panen padi) oleh masyarakat suku Dayak Tamambaloh di Desa Banua Ujung Kecamatan Embaloh Hulu Kabupaten Kapuas Hulu. Hasil penelitian diharapkan dapat menjadi sumber informasi terkait jenis tumbuhan yang digunakan masyarakat untuk ritual adat di Desa Banua Ujung serta pemanfaatannya mengigat pengetahuan lokal yang semakin terdegradasi akibat kemajuan zaman.

\section{METODE PENELITIAN}

Penelitian ini dilaksanakan di Desa Banua Ujung, Kecamatan Embaloh Hulu, Kabupaten Kapuas Hulu dengan waktu selama \pm 4 minggu di lapangan, dimulai dari tanggal 23 maret -23 april 2020. Alat yang digunakan dalam penelitian adalah buku identifikasi tumbuhan karangan K. Heyne II, kuisioner dan tallysheet, alat tulis, kamera, alat perekam serta peta lokasi penelitian. Objek penelitian ini adalah tumbuhan dan masyarakat Suku Dayak Tamambaloh Kabupaten Kapuas Hulu.

Penelitian dilakukan dengan menggunakan metode survey. Pengambilan data menggunakan teknik snowball sampling. Snowball sampling merupakan teknik penentuan sampel yang mula-mula jumlahnya kecil, kemudian membesar (Sugiyono, 2014). Data diperoleh melalui observasi dan wawancara yang dibantu dengan tallysheet. Data yang dikumpulkan berupa data primer dan data sekunder. Data primer terdiri dari nama lokal tumbuhan, bentuk pemanfaatan, bagian yang digunakan dan cara pemanfaatan ataupun pengolahan. Sedangkan untuk data sekunder diperoleh dari literatur, data-data dari kantor desa atau data-data lain yang terkait. Analisis data dalam penelitian ini menggunakan metode deskriptif kualititaif. Berdasarkan data yang diperoleh selanjutnya dilakukan analisis etnobotani, yaitu Famili importance value (FIV), Use Value (UV), Informants Concensus Factor (ICF).

Nilai Kegunaan

Nilai keggunaan (Use Value) diperoleh untuk mengetahui spesies tumbuhan yang memiliki kegunaan tinggi di masyarakat. Semakin besar nilai yang diperoleh artinya spesies tumbuhan tersebut sangat berguna di masyarakat. Nilai keggunaan dihitung berdasarkan rumus berikut ini (Kayani, 2015):

Keterangan:

$$
U V_{s}=\frac{U V_{i s}}{\mathrm{i}_{\mathrm{s}}}
$$

$$
\begin{aligned}
\mathrm{UV}_{\mathrm{S}}= & \text { nilai seluruh penggunaan spesies } \mathrm{s} \\
\mathrm{UV}_{\mathrm{is}}= & \text { nilai penggunaan responden } \mathrm{i} \text { atas } \\
& \text { spesies } \mathrm{s} \\
\mathrm{I}_{\mathrm{S}} \quad \begin{array}{l}
\text { total responden yang diwawancarai } \\
\end{array} & \text { dalam penggunaan spesies }
\end{aligned}
$$

Klasifikasi Nilai Kegunaan (Use Value)

$$
\begin{aligned}
& (<0,05) \quad: \text { Rendah } \\
& (0,05-0,1): \text { Sedang } \\
& (0,1>) \quad \text { : Tinggi }
\end{aligned}
$$

Analisis Famili Impormance Value (FIV)

Digunakan untuk mengetahui famili pada spesies tumbuhan yang paling banyak digunakan (Napagoda, 2015). Dihitung dengan menggunakan rumus berikut: 


$$
F I V=\frac{F C(\text { Famili })}{N} \times 100 \%
$$

Keterangan:

FIV : Nilai (Famili Importance Value)

FC : Jumlah responden yang menyebutkan famili tiap spesies tumbuahnan

$\mathrm{N}$ : Jumlah total responden

Analisis Informants Concensus Factor (ICF)

Digunakan untuk menguji kesepakatan antara responden dan tanaman yang digunakan untuk setiap kategori ritual (Kayani, 2015) dihitung menggunakan rumus berikut:

$$
I C F=\frac{N u r-n t}{N u r-1}
$$

Keterangan:

ICF: Nilai

Nur: Jumlah laporan penggunaan spesies tumbuhan untuk ritual tertentu

Nt : Jumlah spesies tumbuhan yang digunakan untuk ritual tertentu

HASIL DAN PEMBAHASAN

Karakteristik Masyarakat Suku Dayak

Tamambaloh

Desa Banua Ujung merupakan salah satu, dari 10Desa yang berada di Kecamatan Embaloh Hulu, terdiri dari 3 dusun yaitu: Dusun Saligo, Dusun Talie, Dusun Ulak Batu dengan jumlah penduduk total sebanyak 806 jiwa yang berasal dari $232 \mathrm{KK}$ dengan mayoritas masyarakatnya berasal dari suku Dayak Tamambaloh. Dayak Tamambaloh tersebar meliputi disepanjang aliran sungai dan anak sungai Kecamatan Batang Lupar, disepanjang aliran sungai embaloh Kecamatan Embaloh Hulu, disepanjang aliran sungai Palin Kecamatan Embaloh Hilir dan di Nanga Peniung Kecamatan Kalis. Masyarakat Dayak Tamambaloh dalam kehidupan sehari-hari masih kental dengan adat istiadat, dalam pelaksanaanya masih menggunakan tumbuhan yang dipercayai mempunyai makna tertentu pada setiap ritualnya. Pengetahuan masyarakat terhadap pemanfaatan tumbuhan untuk ritual adat diperoleh secara turun-temurun. Ritual adat Pamole Beo adalah bentuk ucapan syukur atas hasil panen yang telah diperoleh, dan memohon kepada I Sampulo (Allah) agar pada tahun yang akan datang menghasilkan panen yang lebih baik. Adapun kegiatan upacara adat pamole beo terdapat tiga tahapan ritual adat yaitu maumpan karue, pamindara banyia, dan malao daun takalong.

\section{Jenis Tumbuhan yang Dimanfaatkan}

Berdasarkan hasil wawancara, diperoleh sebanyak 20 jenis dari 12 famili yang dimanfaatkan oleh Suku Dayak Tamambaloh untuk upacara ritual adat pamole beo. Disajikan pada Tabel 1 . Sementara itu, hasil penelitian Kholifah (2020), di Desa Datah Dian Kabupaten Kapuas Hulu, terdapat 26 spesies dari 17 famili pada proses ritual adat yang dimanfaatkan oleh masya rakat suku Dayak Kayaan dan Dayak Bukat.

Tumbuhan yang dimanfaaatkan oleh masyarakat suku Dayak Tamambaloh dalam upacara adat pamole beo sebanyak 20 spesies, famili terbanyak yang digunakan adalah poaceae dan diikuti oleh arecaceae. Habitus yang paling banyak dimanfaatkan adalah pohon yaitu 7 spesies lalu dikuti oleh liana, bambu dan herba masing-masing sebanyak 3 spesies, sedangkan perdu dan palem sebanyak 2 spesies. Tumbuhan yang tumbuh alami dihutan yang paling banyak digunakan yaitu 15 spesies dan tumbuhan yang sudah dibudidayakan sebanyak 5 spesies. 
Tabel 1. Jenis-Jenis Tumbuhan Yang Dimanfaatkan Oleh Masyarakat Dayak Tamambaloh Desa Banua Ujung Kabupaten Kapuas Hulu (The species of plants used by the Dayak Tamambaloh community of Banua Ujung Village, Kapuas Hulu Regency)

\begin{tabular}{|c|c|c|c|c|c|c|c|}
\hline No & Nama Lokal & $\begin{array}{c}\text { Nama } \\
\text { Indonesia }\end{array}$ & Nama Ilmiah & Famili & Habitus & Habitat & $\begin{array}{l}\text { Status di } \\
\text { Alam }\end{array}$ \\
\hline 1. & Akar Sasait & Pilantas & Uncaria nervosa Elmer. & Rubiaceae & Liana & Hutan & $\mathrm{L}$ \\
\hline 2. & Andungge & Daun Biru & Licuala spinosa $\mathrm{L}$ & Arecaceae & Palem & Hutan & $\mathrm{L}$ \\
\hline 3. & Ase & Padi & Oryza sativa $\mathrm{L}$. & Poaceae & Herba & Hutan & B \\
\hline 4. & Bulok Paring & $\begin{array}{l}\text { Bambu } \\
\text { Betung }\end{array}$ & $\begin{array}{l}\text { Dendrocalamus asper } \\
\text { (schultes F.) Backer ex } \\
\text { heyne }\end{array}$ & Poaceae & Bambu & Hutan & $\mathrm{L}$ \\
\hline 5. & Bulok Toto & & $\begin{array}{l}\text { Schizostazchyum } \\
\text { brachyladum kurz }\end{array}$ & Poaceae & Bambu & Hutan & $\mathrm{L}$ \\
\hline 6. & Bulok Unti & $\begin{array}{l}\text { Bambu } \\
\text { Munti }\end{array}$ & Schizostachyum sp. & Poaceae & Bambu & Hutan & $\mathrm{L}$ \\
\hline 7. & Boulu & Sirih & Piper betle $\mathrm{L}$ & Piperaceae & Liana & Perkarangan & B \\
\hline 8. & $\begin{array}{l}\text { Daun } \\
\text { Takalong }\end{array}$ & Terap & $\begin{array}{l}\text { Artocarpus } \\
\text { odoratissimus }\end{array}$ & Moraceae & Pohon & Hutan & $\mathrm{L}$ \\
\hline 9 & Kakas & $\begin{array}{l}\text { Paku } \\
\text { Lemiding }\end{array}$ & $\begin{array}{l}\text { Stenochlaena palustris } \\
\text { (Burm.F.) Bedd. }\end{array}$ & Blechnaceae & Herba & Hutan & $\mathrm{L}$ \\
\hline 10 & Litak & Pulai & Alstonia scholaris R.Br. & $\begin{array}{l}\text { Apocynacea } \\
\text { e }\end{array}$ & Pohon & Hutan & $\mathrm{L}$ \\
\hline 11. & Loan & Meranti & Shorea sp. & $\begin{array}{l}\text { Dipterocarpa } \\
\text { ceae }\end{array}$ & Pohon & Hutan & $\mathrm{L}$ \\
\hline 12 & Pulut & Padi Ketan & $\begin{array}{l}\text { Oryza sativa var. } \\
\text { glutinosa }\end{array}$ & Poaceae & Herba & Hutan & B \\
\hline 13. & Pohon Tuak & Enau & Arenga pinnata Merr. & Arecaceae & Palem & Hutan & $\mathrm{L}$ \\
\hline 14 & Pulang & Mahang & $\begin{array}{l}\text { Macaranga mauritiana } \\
\text { Bojer ex Baill. }\end{array}$ & $\begin{array}{l}\text { Euphorbiace } \\
\text { ae }\end{array}$ & Pohon & Hutan & $\mathrm{L}$ \\
\hline 15 & Raru & Raru & $\begin{array}{l}\text { Cotylelobium } \\
\text { melanoxylon }\end{array}$ & $\begin{array}{l}\text { Dipterocarpa } \\
\text { ceae }\end{array}$ & Pohon & Hutan & $\mathrm{L}$ \\
\hline 16 & Singkara & Pinang & Areca catechu $\mathrm{L}$. & Arecaceae & Pohon & Pekarangan & B \\
\hline 17 & Tabalian & Ulin & $\begin{array}{l}\text { Eusideroxylon zwageri } \\
\text { Teijsm.et Binnend }\end{array}$ & Lauraceae & Pohon & Hutan & $\mathrm{L}$ \\
\hline 18. & Tembako & Tembakau & Nicotiana tabacum $\mathrm{L}$. & Solanaceae & Perdu & Hutan & B \\
\hline 19. & Untok-Untok & Aka lundang & $\begin{array}{l}\text { Poiskilospermu } \\
\text { Suaveolens (Blume) } \\
\text { Merr. }\end{array}$ & Urticaceae & Perdu & Hutan & $\mathrm{L}$ \\
\hline 20 & Uwe Papatik & $\begin{array}{l}\text { Rotan } \\
\text { Batang }\end{array}$ & $\begin{array}{l}\text { Daemonorops } \\
\text { macroptera }\end{array}$ & Arecaceae & Liana & Hutan & $\mathrm{L}$ \\
\hline
\end{tabular}

Keterangan: $L=$ Liar $B=$ Budidaya

\section{Pemanfaatan Tumbuhan Untuk Proses Upacara Adat Pamole Beo}

Pamole Beo biasa dilaksanakan setiap tahun pada bulan juli setelah panen raya dan menjelang masyarakat Dayak Tamambaloh membuka lahan baru untuk berladang. Tumbuhan yang dimanfaatkan terdapat 20 spesies dari 12 famili. Adapun tahapan kegiatan ritual adat pamole beo adalah sebagai berikut.

\section{1). Maumpan Karue}

Maumpan karue adalah ritual yang pertama dilakukan da Upacara Pamole Beo terdapat 3 kategori terkait jenis ritual adat. lam kegiatan pamole beo, yaitu memberikan sesajen kepada bendabenda yang dianggap wujud atau lambang kehadiran arwah nenek moyang. Karue ini dapat berwujud batu, kayu, bambu, tanah liat maupun 
mangkok, sebagai pertanda untuk meminta izin bahwa akan melaksanakan upacara adat pamole beo.

\section{2). Pamindara Banyia}

Ritual pamindara banyia merupakan inti dari kegiatan Pamole Beo. Pamindara artinya upacara dan banyia artinya benih. Pamindara banyia diawali dengan istilah mangalonggang (pembacaan doa/mantra) yaitu, memanggil roh padi atau arwah nenek moyang untuk diajak makan bersama dalam pesta pamole beo sebagai lambang persembahan kepada I Sampulo (Allah). Karena telah membantu menjaga padi, sehingga padi dapat tumbuh subur dan dan panen berhasil. Selain itu juga, memberi makan kepada roh-roh yang jahat, agar tidak menganggu. Setelah itu dilanjutkan dengan istilah adat manjanang, yaitu mengucapkan puji-pujian kepada roh padi atau arwah nenek moyang yang diucapkan dan dinyanyikan oleh ibu-ibu secara bersama-sama. Manjanang ini dilakukan satu malam suntuk.

\section{Malao Daun Takalong}

Malao daun takalong diawali dengan menurunkan kalangkang yang tadi berisi sesajen dan diletakkan dipendopo rumah betang. Hal itu menandakan masyarakat Dayak Tamambaloh di Desa Banua Ujung akan berpantang. Setelah 3 hari berpantang dilanjutkan dengan menghanyutkan talayong di sungai Tamambaloh, talayong berisi sesajen berupa tuak, lemang, kue kalame, sirih, dan pinang.
Menghanyutkan talayong disertai dengan mengucapkan mantera dan bernyanyi oleh ibu-ibu yang usianya relatif tua. Menurut Istianingrum (2018), mantra digunakan sebagai sarana untuk berkomunikasi dengan Tuhan, Dewa, Leluhur, atau mahluk gaib lainnya. Mantera terus diucapkan sampai talayong yang dihanyutkan di sungai tidak kelihatan lagi, dengan tujuan untuk mengusir roh jahat yang menyebabkan panen gagal dan segala kesialan hanyut dan hilang bersama talayong, tersebut.

Jenis Tumbuhan Yang Dimanfaatkan Berdasarkan Habitus

Habitus yang paling banyak dimanfaatkan adalah pohon yaitu 7 spesies dengan persentase $35 \%$. Sementara itu, penelitian Kuni et al. (2015) di Desa Tapang Kabupaten Sekadau, terdapat 4 habitus yaitu herba 1 spesies, perdu 3 spesies, pohon 3 spesies dan semak 2 spesies oleh Suku Dayak Kerabat. Faktor yang menyebabkan persentase tingkat penggunaan tumbuhan berdasarkan habitus berbeda dan pohon adalah yang tertinggi, karena tingkat pohon bagian digunakan adalah batangnya, baik itu jenis batang yang tahan lama seperti ulin untuk membuat patung, maupun seperti rotan dan bambu yang mudah dibawa dan ringan yang digunakan hanya pada saat acara berlangsung. Pada pelaksanaan ritual adat, jenis tumbuhan yang berhabitus pohon harus ada, karena dipercayai memiliki makna tertentu dan pemanfaatannya sudah turun-temurun. 


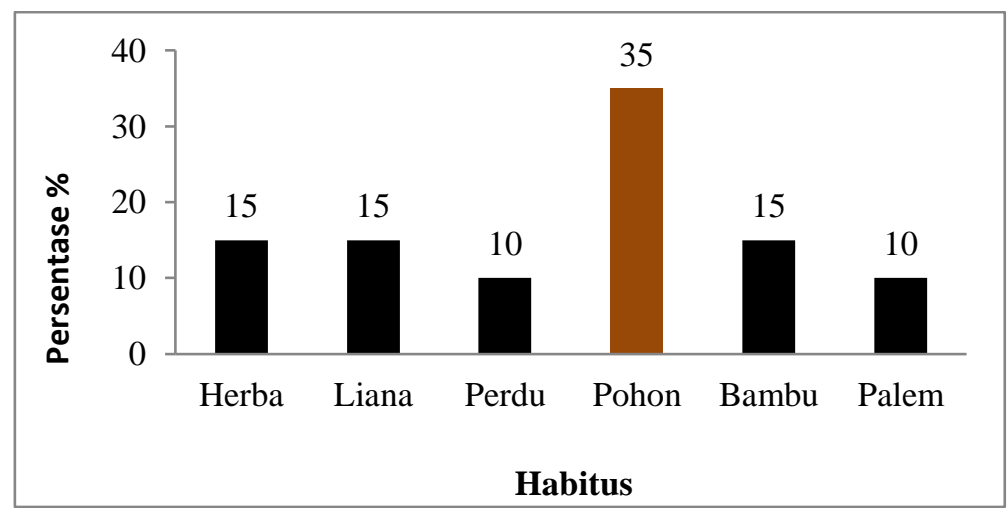

Gambar 1. Persentase Tumbuhan Yang Dimanfaatkan Berdasarkan Habitus

Jenis Tumbuhan Yang Dimanfaatkan

\section{Berdasarkan Status Di Alam}

Tumbuhan yang digunakan ada yang masih tumbuh alami dihutan (tumbuh liar) dan ada yang sudah dibudidayakan. Tumbuhan yang tumbuh alami dihutan yang paling banyak digunakan dengan persentase sebanyak $75 \%$ dan tumbuhan yang sudah dibudidayakan sebanyak $25 \%$. Perbedaaan persentase yang sangat signifikan, antara tumbuhan yang tumbuh alami dihutan dan yang sudah dibudidayakan. Karena kondisi lingkungan hutan masyarakat di Desa Banua Ujung masih lestari dan pemukiman masyarakat masih dekat kawasan dengan hutan, yang menyediakan kebutuhan untuk masyarakat masih banyak baik, untuk pelaksanaan ritual, dan kelangsungan hidup sehari-hari.

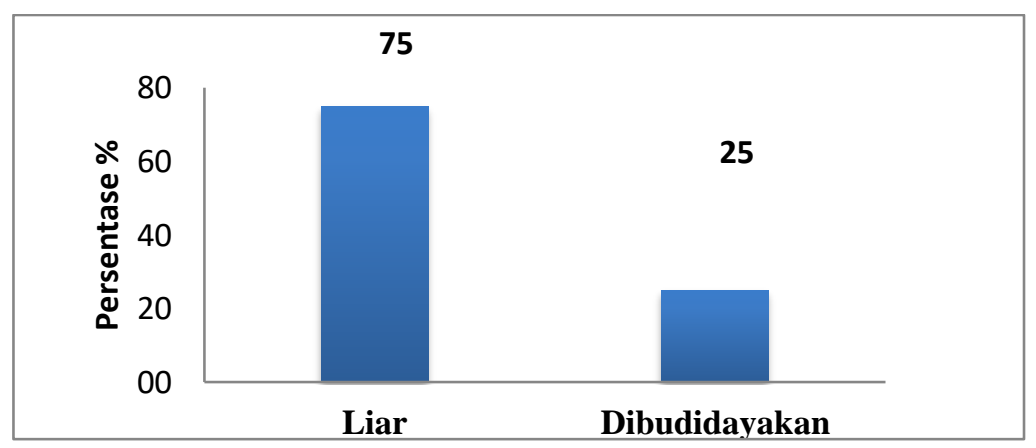

Gambar 2. Persentase Jenis Tumbuhan Yang Dimanfaatkan Berdasarkan Status Di Alam

Jenis Tumbuhan Berdasarkan Bagian Yang Dimanfaatkan Untuk Ritual Adat

Bagian tumbuhan yang paling banyak dimanfaatkan untuk upacara ritual adat oleh masyarakat Dayak Tamambaloh adalah batang yaitu sebanyak $40 \%$ dan diikuti oleh daun sebanyak $20 \%$. Perbedaan pemanfaatan bagian tumbuhan yang signifikan ini disebabkan karena pemanfaatan bagian batang seperti rotan dan bambu di Desa Banua Ujung mudah didapatkan dan diolah, sementara daun memiliki bentuk 
dan tekstur yang lebih mudah diolah dan mudah diambil. Selain itu masyarakat suku Dayak Tamambaloh, memiliki Nilai kepercayaan, dan aturan-aturan khusus, terkait pemanfaatkan bagian tumbuhan berupa batang. Sehingga sampai sekarang dijadikan acuan oleh masyarakat Dayak Tamambaloh untuk memanfaatkan berdasarkan pengetahuan yang sudah secara turun-temurun. Sedangkan hasil penelitian Purwanti (2017), Etnobotani pada proses ritual adat masyarakat suku Saluan di Desa Pasokan Kabupaten Tojo Una-Una tumbuhan yang dimanfaatkan paling banyak yaitu daun dan batang sebanyak $19 \%$.

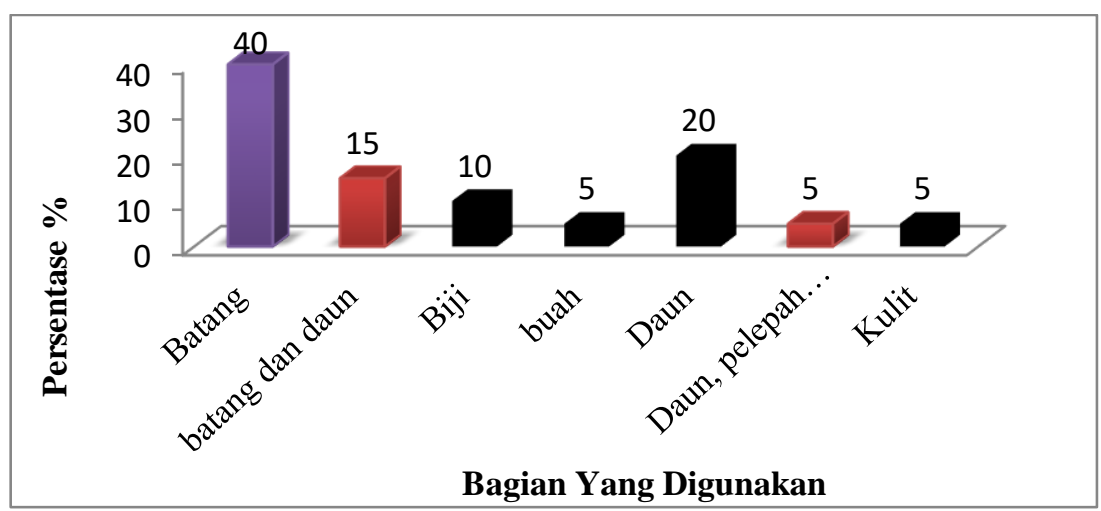

\section{Gambar 3. Persentase Tumbuhan Berdasarkan Bagian Yang Dimanfaatkan Use Value (Nilai Kegunaan)}

Use value (UV) diperoleh untuk mengetahui spesies tumbuhan yang memiliki kegunaan tinggi dimasyarakat. Pada penelitian ini terdapat 20 spesies tumbuhan yang digunakan masyarakat Dayak Tamambaloh dalam pemanfaatan tumbuhan untuk kegiatan ritual adat yang dilakukan wawancara pada 20 responden. Nilai kegunaan menunjukkan bahwa bulok unti (Schizostazchyum sp), pohon tuak (A. pinnata Merr.), pulut (Oryza sativa var. glutinosa), raru ( $C$. melanoxylon L.) memiliki nilai kegunaan tertinggi dengan persentase sebanyak (1) dan masing-masing memiliki 3 kegunaan dari 3 macam kegunaan ritual yang ada. Berarti masyarakat banyak memanfaatkan bulok unti, raru, pohon tuak dan pulut utuk kegiatan ritual adat. Sedangkan tumbuhan dengan $(U V)$ terendah adalah Poiskilospermum Suaveolens (Blume) Merr. dengan nilai $U V(0,75)$. Berarti tidak semua masyarakat mengguakan untok-untok untuk ritual adat pamindara banyia, Hal ini dikarenakan tumbuhan tersebut tidak bersifat wajib atau dapat digantikan dengan tumbuhan lain seperti kakas dan akar sasait pelaksaan ritual. 
Tabel 2. Nilai Kegunaan (Use Value)

\begin{tabular}{lllc}
\multicolumn{1}{c}{ No } & \multicolumn{2}{c}{ Nama Tumbuhan } & Nilai Kegunaan Total \\
\cline { 2 - 3 } & \multicolumn{1}{c}{ Nama Lokal } & \multicolumn{1}{c}{ Nama Indonesia } & $(\mathbf{3})$ \\
\hline 1 & Akar Sasait & Pilantas & $\mathbf{( 4 )}$ \\
2 & Andungge & Palem kipas & 0,85 \\
3 & Ase & Padi & 0,85 \\
4 & Bulok Paring & - & 0,85 \\
5 & Bulok Toto & - & 0,85 \\
6 & Bulok Unti & Bambu lemang & 0,85 \\
7 & Boulu & Sirih & 1 \\
8 & Daun Takalong & Terap & 0,85 \\
9 & Kakas & Paku limiding & 0,85 \\
10 & Litak & Pulai & 0,85 \\
11 & Loan & Meranti & 0,85 \\
12 & Pulut & Beras ketan & 0,85 \\
13 & Pohon Tuak & Enau & 1 \\
14 & Pulang & Mahang & 1 \\
15 & Raru & Raru & 0,85 \\
16 & Singkara & Pinang & 1 \\
17 & Tabalian & Ulin & 0,85 \\
18 & Tembako & Tembakau & 0,85 \\
19 & Untok - Untok & Aka lundang & 0,85 \\
20 & Uwe Papatik & Rotan batang & 0,75 \\
\hline
\end{tabular}

\section{Analisis Famili Importance Value (FIV)}

Famili importance value (FIV) untuk mengetahui famili tumbuhan yang paling banyak digunakan (Napagoda et $a l$, 2015). Nilai FIV akan ditampilkan pada Tabel. 4. Famili dengan nilai FIV paling tinggi adalah Arecaceae, Dipterocarpaceae, Poaceae dengan nilai $100 \%$, artinya merupakan famili yang paling banyak dimanfaatkan oleh masyarakat untuk kegiatan ritual adat.

Hal ini dikarenakan famili Arecaceae, Dipterocarpaceae, Poaceae, kelompok tumbuhan yang dipercayai memiliki makna sebagai sarana perantara doa dan persembahan untuk arwah nenek moyang, yang sudah dimanfaatkan secara turun- temurun. Selain itu, keberadaannya masih mudah didapatkan sekitar hutan adat dan pengolahannya cukup mudah. Sedangkan yang paling rendah sebanyak $65 \%$ berarti hanya beberapa masyarakat Dayak Tamambaloh yang menggunakan tumbuhan dari famili Urticaceae yaitu Poiskilospermum Suaveolens (Blume) Merr. Karena menurut mereka penggunaanya bersifat tidak wajib pada saat ritual adat berlangsung atau dapat digantikan dengan tumbuhan lain. Sementara itu, hasil penelitian (Lily et al. 2019) etnobotani tumbuhan ritual di keraton Yogyakarta menyatakan famili yang paling banyak dimanfaatkan adalah poaceae dan zingiberaceae $(7,44)$ 
Tabel 3. Nilai Penting Keluarga (Analisis Famili Importance Value (FIV)

\begin{tabular}{|c|c|c|c|c|c|}
\hline No & Famili & Fiv & No & Famili & Fiv \\
\hline 1. & Arecaceae & 100 & 7. & Moraceae & 85 \\
\hline 2. & Apocynaceae & 85 & 8. & Piperaceae & 85 \\
\hline 3. & Blechnaceae & 85 & 9. & Poaceae & 100 \\
\hline 4. & Dipterocarpaceae & 100 & 10. & Rubiaceae & 85 \\
\hline 5. & Euphorbiaceae & 85 & 11. & Solanaceae & 85 \\
\hline 6. & Lauraceae & 85 & 12. & Urticaceae & 65 \\
\hline
\end{tabular}

\section{Nilai Faktor Konsensi Informan} (Informants Concensus Factor (ICF))

Informants Concensus Factor (ICF) digunakan untuk mengetahui kesepakatan antara responden dan tanaman yang digunakan untuk setiap kategori ritual (Kayani et al. 2015). Table 5 menunjukkan terdapat 3 jenis ritual adat pamole beo dengan nilai $I C F$ paling tinggi adalah upacara adat Malao Daun Takalong sebanyak $(0,68)$ artinya masyarakat suku Dayak Tamambaloh memiliki kesepakatan bahwa Daemonorops macroptera (Miquel) becari, Artocarpus odoratissimus, Schizostachyum sp, Areca catechu L, Areca pinnata Merr, Oryza sativa var. Glutinosa, sering digunakan masyarakat untuk ritual malao daun takalong. Hal ini dikarenakan ritual malao dau takalong adalah ritual yang harus dilakukan karena menandakan berakhirnya pamole beo dan dimulainya masa berladang yang baru.

Sehingga memerlu tumbuhan yang dipercayai sebagai sarana mengusir roh jahat yang menyebabkan panen gagal dan segala kesialan hanyut dan hilang bersama talayong tersebut dengan cara memberikan sesajen. Menurut masyarakat suku Dayak Tamambaloh kebiasaan ini sudah dilakukan sejak dahulu secara turuntemurun dan tumbuhan yang digunakan tidak bisa digantikan dengan tumbuhan lain.

Tabel 4. Informants Concensus Factor (ICF)

\begin{tabular}{llllll}
\hline No & Upacara adat & Jenis Ritual Adat & $\begin{array}{l}\text { Jumlah } \\
\text { Pengguna }\end{array}$ & $\begin{array}{l}\text { Jumlah } \\
\text { Tumbuhan }\end{array}$ & ICF \\
\hline 1. & Pamole Beo & Maumpan Karue & 18 & 9 & 0,57 \\
& & 17 & 16 & 0,21 \\
& & Pamindara Banyia & 20 & 7 & 0,68 \\
\hline
\end{tabular}

\section{Kesimpulan}

Tumbuhan yang dimanfaatkan oleh masyarakat Dayak Tamambaloh untuk kegiatan upacara adat pamole beo sebanyak 20 spesies yang berasal dari 12 famili dan habitus yang paling banyak dimanfaatkan adalah tingkat pohon sebanyak $35 \%$ (7 spesies dari total 20 spesies yang ada). Batang merupakan bagian tumbuhan yang paling banyak dimanfaatkan sebanyak 8 spesies (40\%). Jenis Tumbuhan yang paling banyak dimanfaatkan berdasarkan status di alam adalah tumbuhan alami di hutan dengan persentase $(75 \%)$. Nilai 
kegunaan (use value) tumbuhan oleh masyarakat suku Dayak Tamambaloh dengan nilai tertinggi yaitu (1), jenis tumbuhan yang digunakan mempunyai nilai dan makna yang penting sebagai alat dan pelengkap pelaksanaan upacara adat, jenis tumbuhannya adalah bulok unti (Schizostachyum sp), pohon tuak (Arenga pinnata Merr.), pulut (Oryza sativa Var. glutinosa), dan raru (Cotylelobium melanoxylon) untuk 3 tahapan ritual adat pada upacara pamole beo. Analisis Famili Importance Value (FIV) tertinggi adalah Arecaceae, Dipterocarpaceae, dan Poaceae dengan nilai $100 \%$, ketersediaan spesies pada setiap famili cukup banyak di sekitar lingkungan, baik tanaman budidaya maupun liar. Informants Concensus Factor (ICF) tertinggi adalah ritual adat malao daun takalong yaitu dengan nilai $(0,94)$, kesepakata dan kepercayaan masyarakat bahwa setiap jenis tumbuhan memiliki nilai-nilai spiritual dan makna tersendiri dalam riual adat yang didapatkan secara turun-temurun.

\section{Saran}

Setiap upacara ritual adat oleh masyarakat Dayak Tamambaloh selalu menggunakan tumbuhan, upaya budidaya ini perlu dilakukan untuk menghidari resiko kepunahan beberapa spesies tumbuhan. Maka perlu dilakukan upaya budidaya terhadap tumbuhan untuk penunjang ritual adat yang keberadaannya mulai susah didapatkan.

\section{DAFTAR PUSTAKA}

Gaby N, Mardiana, Suhdiah. (2019). Kajian Etnobotani Upacara Adat Mandar Di Provinsi Sulawesi Barat Kabupaten Polewali. Jurnal Bioma, 1(1):16-23
Iswandono dan Elisa. 2015 Pengetahuan Etnobotani Suku Manggarai Dan Implikasinya Terhadap Pemanfaatan Tumbuhan Hutan Di Pegunungan Ruteng. Jurnal Ilmu Pertanian Indonesia 20(3): 171-181.

Istianingrum R. 2018. Mantra Tipong Tawar Dalam Tradisi Upacara Pertanian Dayak Paser Sebagai Proyeksi Kehidupan Masyarakat. Jurnal Bahasa dan Budaya. 2(1):19- 33

Kayani S, Mushtaq A, Shazia S, Zabta KS, Muhammed Z, Ghulam Y, Manzoor H, dan Tahira B. 2015. Ethnobotany of Medicinal Plants Among the Communities of Alpine and Subalpine Regions of Pakistan. Journal of Ethnopharmacology 164:186-202

Kholifah. 2020. Etnobotani Ritual Adat Suku Dayak di Sekitar Hutan di Desa Datah Dian Kabupaten Kapuas Hulu. Jurnal Hutan Lestari 8(2): 379-395.

Lily S, Farah W, Rina S. 2019. Etnobotani Tumbuhan Ritual Yang Digunakan Pada Upacara Jamasan Di Keraton Yogyakarta. Jurnal Biologi Makasar. 4(2): 99-106.

Napagoda MT, Thamudi S, dan Diroshi F. 2018. An Ethnobotanical Study of the Medicinal Plants Used as AntiInflammatory Remedies in Gampaha District, Western Province, Sri Langka. Journal Scientifica. Vol 2018, Article ID 9395052: 1-8

Purwanti. 2017. Studi Etnobotani Pada Proses Ritual Adat Masyarakat Suku Saluan Di Desa Pasokan Kabupaten Tojo Una-Una. Jurnal Biocelebes 11(1):46-60. 
JURNAL HUTAN LESTARI (2021)

Vol. 9 (2): 246 - 261

Sugiyono. (2014). Metode Penelitian Pendidikan Pendekatan Kuantitatif Kualitatif Dan R\&D. Bandung.

Yuniati, E., \& Alwi, M. (2010) . Etnobotani Keanekaragaman Jenis
Tumbuhan Obat Tradisional Dari Hutan di Desa Pakuli Kecamatan Gumbasa Kabupaten Donggala Sulawesi Tengah. Biocelebes,4(1),6. 


\section{Lampiran}

Tabel 5. Jenis-Jenis Tumbuhan Yang Dimanfaatkan Oleh Dayak Tamambaloh Berdasarkan Bagian Yang Dimanfaatkan, Makna Dan Cara Pemanfaatan Atau Pengolahan Upacara Adat Pamole Beo Oleh Masyarakat Suku Dayak Tamambaloh (Types of Plants Utilized by Dayak Tamambaloh Based on the Utilized Part, Meaning and Method of Utilization or Processing of Traditional Pamole Beo Ceremonies by the Dayak Tamambaloh Tribe)

\begin{tabular}{|c|c|c|c|c|c|c|c|c|}
\hline \multirow[t]{2}{*}{ No } & \multirow{2}{*}{$\begin{array}{l}\text { Upacara } \\
\text { Adat }\end{array}$} & \multirow[t]{2}{*}{ Jenis Ritual } & \multicolumn{3}{|c|}{ Jenis Tumbuhan } & \multirow{2}{*}{$\begin{array}{l}\text { Bagian } \\
\text { Yang } \\
\text { Digunakan }\end{array}$} & \multirow[t]{2}{*}{ Makna Simbolis } & \multirow[t]{2}{*}{ Cara Penggunaan } \\
\hline & & & $\begin{array}{l}\text { Nama } \\
\text { Lokal }\end{array}$ & $\begin{array}{l}\text { Nama } \\
\text { Indonesia } \\
\end{array}$ & Nama Ilmiah & & & \\
\hline (1) & (2) & (3) & (4a) & $(4 b)$ & $(4 c)$ & (5) & (6) & (7) \\
\hline \multirow[t]{6}{*}{1.} & $\begin{array}{l}\text { Pamole } \\
\text { Beo }\end{array}$ & $\begin{array}{l}\text { Maumpan } \\
\text { Karue }\end{array}$ & Tabalian & Ulin & $\begin{array}{l}\text { Eusideroxylon } \\
\text { Zwageri Teijsm.et } \\
\text { Binnend }\end{array}$ & Batang & $\begin{array}{l}\text { Untuk patung } \\
\text { berbentuk } \\
\text { manusia }\end{array}$ & Diolah \\
\hline & & & Bulok Toto & - & $\begin{array}{l}\text { Schizostazchyum } \\
\text { brachyladum kurz }\end{array}$ & Batang & $\begin{array}{l}\text { Untuk memasak } \\
\text { lemang, kalame } \\
\text { dan untuk } \\
\text { menyimpan tuak }\end{array}$ & Diolah \\
\hline & & & Andungge & Palem kipas & Licuala spinosa $\mathrm{L}$ & Daun & $\begin{array}{l}\text { Daunnya salah } \\
\text { satu syarat untuk } \\
\text { minuman arwah }\end{array}$ & Diolah \\
\hline & & & $\begin{array}{l}\text { Uwe } \\
\text { Papatik }\end{array}$ & $\begin{array}{l}\text { Rotan } \\
\text { batang }\end{array}$ & $\begin{array}{l}\text { Daemonorops } \\
\text { macroptera } \\
\text { (Miquel) becari }\end{array}$ & Batang & $\begin{array}{l}\text { Melambangkan } \\
\text { kekuatan dan } \\
\text { persatuan } \\
\text { masyarakat } \\
\text { Tamambaloh }\end{array}$ & Diolah \\
\hline & & & $\begin{array}{l}\text { Daun } \\
\text { Takalong }\end{array}$ & Terap & $\begin{array}{l}\text { Artocarpus } \\
\text { odoratissimus }\end{array}$ & Daun & $\begin{array}{l}\text { Tempat makanan } \\
\text { bagi arwah }\end{array}$ & $\begin{array}{l}\text { Digunakan } \\
\text { langsung }\end{array}$ \\
\hline & & & Boulu & Sirih & Piper betle L. & Daun & $\begin{array}{l}\text { Daunnya salah } \\
\text { satu syarat untuk } \\
\text { makanan arwah }\end{array}$ & $\begin{array}{l}\text { Digunakan } \\
\text { langsung }\end{array}$ \\
\hline
\end{tabular}




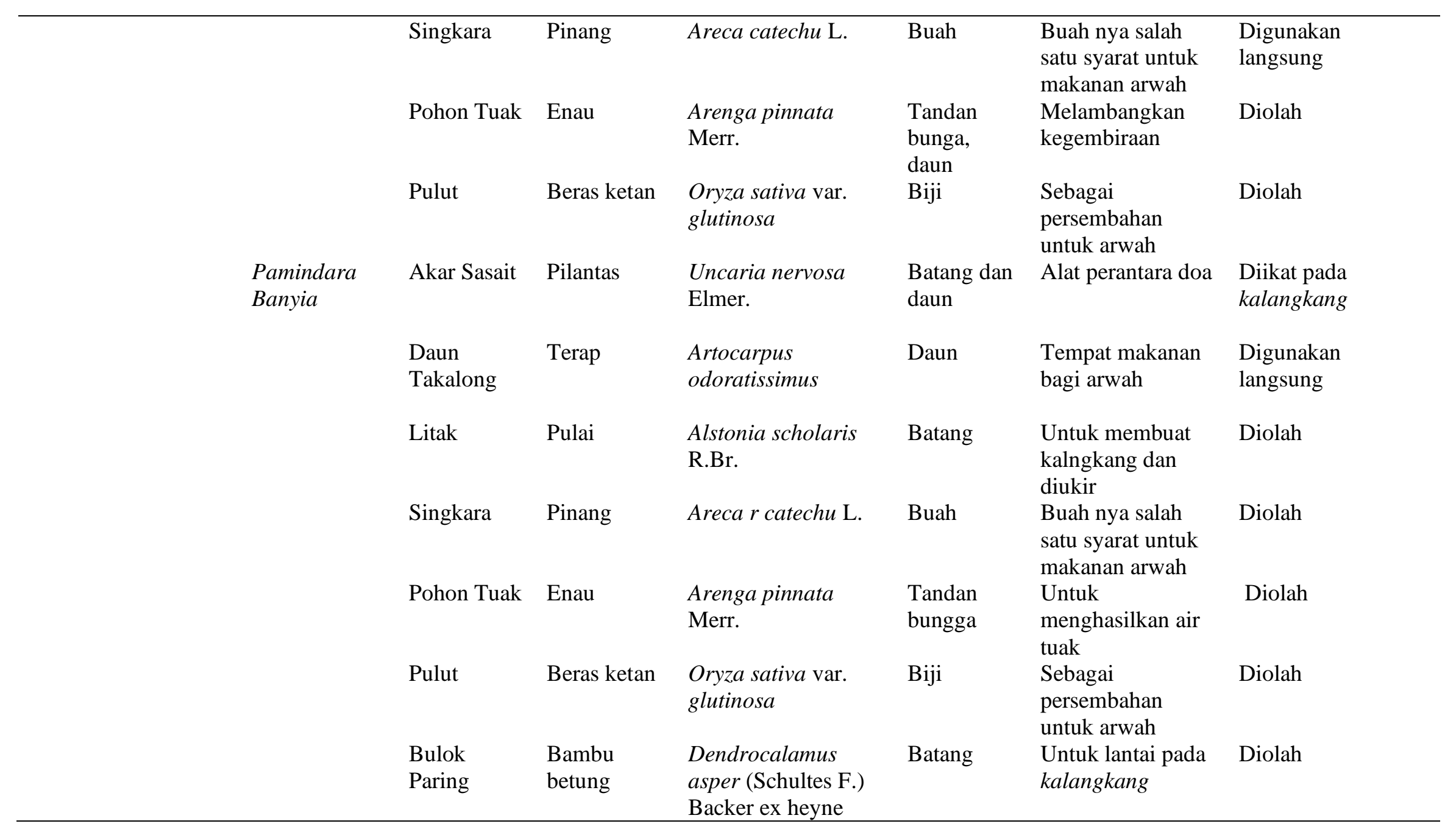




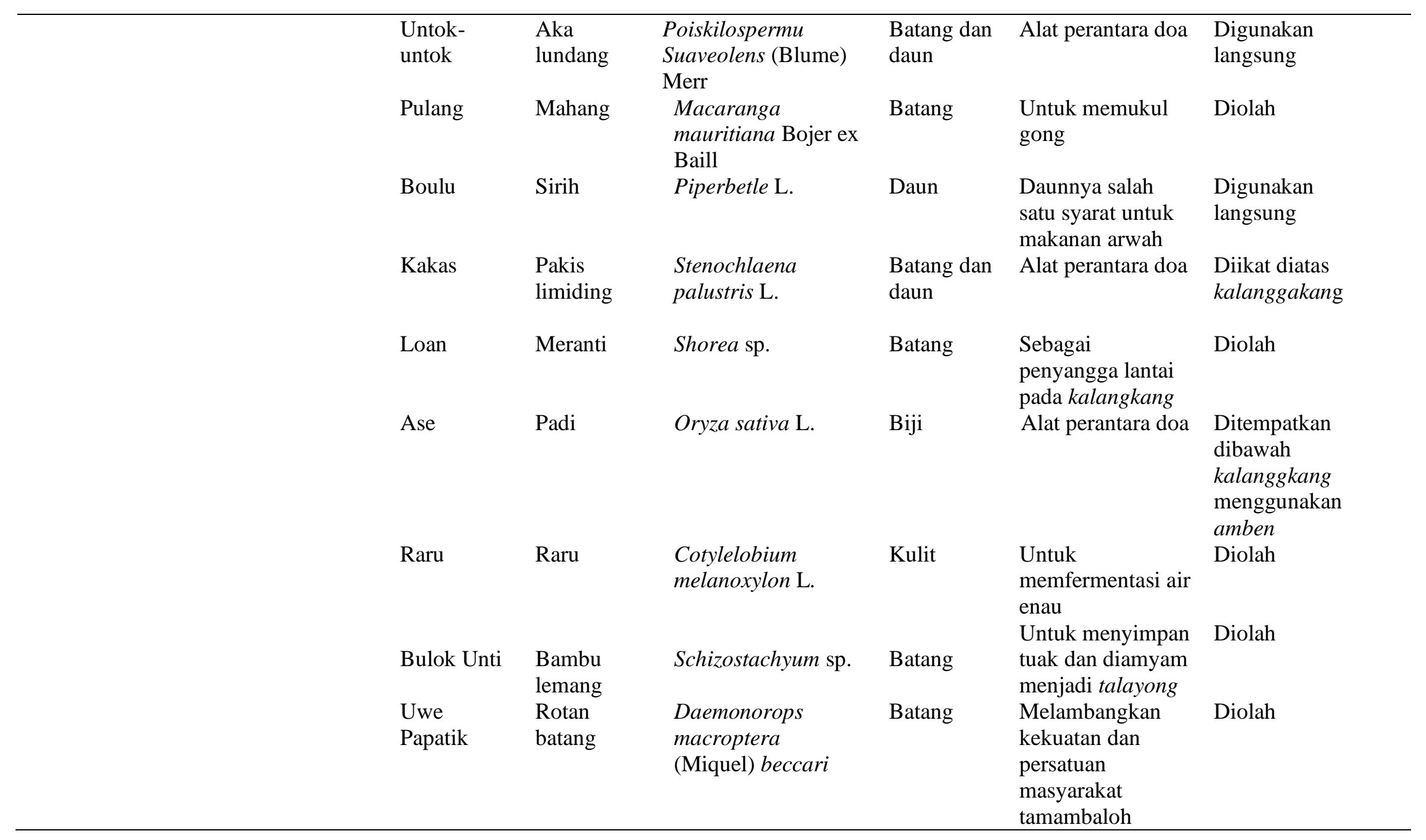




\begin{tabular}{|c|c|c|c|c|c|c|c|}
\hline & & Tembakao & Tembakau & $\begin{array}{l}\text { Nicotiana tabacum } \\
\text { L. }\end{array}$ & Daun & $\begin{array}{l}\text { Salah satu syarat } \\
\text { untuk memanggil } \\
\text { arwah }\end{array}$ & $\begin{array}{l}\text { Diletakan dalam } \\
\text { kalangkang }\end{array}$ \\
\hline \multirow[t]{7}{*}{2.} & $\begin{array}{l}\text { Malao Daun } \\
\text { Takalong }\end{array}$ & $\begin{array}{l}\text { Uwe } \\
\text { Papatik }\end{array}$ & $\begin{array}{l}\text { Rotan } \\
\text { batang }\end{array}$ & $\begin{array}{l}\text { Daemonorops } \\
\text { macroptera } \\
\text { (Miquel) becari }\end{array}$ & Batang & $\begin{array}{l}\text { Melambangkan } \\
\text { kekuatan dan } \\
\text { persatuan } \\
\text { masyarakat } \\
\text { Tamambaloh }\end{array}$ & Diolah \\
\hline & & $\begin{array}{l}\text { Daun } \\
\text { Takalong }\end{array}$ & Terap & $\begin{array}{l}\text { Artocarpus } \\
\text { odoratissimus }\end{array}$ & Daun & $\begin{array}{l}\text { Tempat makanan } \\
\text { bagi arwah }\end{array}$ & $\begin{array}{l}\text { Digunakan } \\
\text { langsung }\end{array}$ \\
\hline & & Bulok Unti & $\begin{array}{l}\text { Bambu } \\
\text { lemang }\end{array}$ & Schizostachyum sp. & Batang & $\begin{array}{l}\text { Untuk menyimpan } \\
\text { tuak dan diamyam } \\
\text { menjadi talayong }\end{array}$ & Diolah \\
\hline & & Singkara & Pinang & Areca catechu L. & Buah & $\begin{array}{l}\text { Buah nya salah } \\
\text { satu syarat untuk } \\
\text { makanan arwah }\end{array}$ & Diolah \\
\hline & & Raru & Raru & $\begin{array}{l}\text { Cotylelobium } \\
\text { melanoxylon }\end{array}$ & Kulit & $\begin{array}{l}\text { Untuk } \\
\text { memfermentasi air } \\
\text { enau }\end{array}$ & Diolah \\
\hline & & Pohon Tuak & Enau & Areca pinnata Merr & $\begin{array}{l}\text { Tandan } \\
\text { bungga }\end{array}$ & $\begin{array}{l}\text { Untuk } \\
\text { menghasilkan air } \\
\text { tuak }\end{array}$ & Diolah \\
\hline & & Pulut & Beras ketan & $\begin{array}{l}\text { Oryza sativa var. } \\
\text { glutinosa }\end{array}$ & Biji & $\begin{array}{l}\text { Sebagai } \\
\text { persembahan } \\
\text { untuk arwah }\end{array}$ & Diolah \\
\hline
\end{tabular}

